\title{
Scanning microelectrochemical characterization of the anti-corrosion performance of inhibitor films formed by 2-mercaptobenzimidazole on copper
}

\author{
Javier Izquierdo ${ }^{1}$, Juan José Santana ${ }^{2}$, Sergio González ${ }^{1}$ and Ricardo M. Souto ${ }^{1,3}$ \\ ${ }^{1}$ Department of Physical Chemistry, University of La Laguna, E-38207 La Laguna, Tenerife, Canary \\ Islands, Spain. \\ 2 Department of Process Engineering, University of Las Palmas de Gran Canaria, Campus \\ Universitario de Tafira, E-35017 Las Palmas de Gran Canaria, Canary Islands, Spain. \\ ${ }^{3}$ Instituto de Materiales y Nanotecnologías, University of La Laguna, E-38200 La Laguna, Tenerife, \\ Canary Islands, Spain
}

\begin{abstract}
:
The aim of this work is to explore the applicability of the scanning electrochemical microscope (SECM) to characterize the inhibiting effect of 2-mercaptobenzimidazole against the corrosion of copper. SECM was operated in the feedback mode by using ferrocene-methanol as redox mediator, and the sample was left unbiased at all times. The kinetic changes in the corrosion processes were monitored over time from the Z-approach curves. Furthermore, inhibitor-modified copper samples presenting various surface finishes were imaged by SECM and the scanning vibrating electrode technique (SVET), allowing changes both in the surface activity of metal-inhibitor films and in the extent of corrosion attack to be spatially-resolved. Differences in the local electrochemical activity between inhibitor-free and inhibitor-covered areas of the sample were successfully monitored.
\end{abstract}

Keywords: Corrosion inhibition; Scanning electrochemical microscopy (SECM); Scanning Vibrating Electrode Technique (SVET); Copper; Mercaptobenzimidazole (MBI). 


\section{1.- Introduction}

Benzotriazole (BTAH) and 2-mercaptobenzimidazole (MBI) are the most widely employed inhibitors for the anticorrosion protection of metals, their use ranging from copper and its alloys [15], to steels [6-10], and to zinc $[11,12]$. They effectively protect these metals in various aggressive environments, and the most accepted mechanism to describe their operation involves the formation of a chemisorbed layer of these organic molecules on the metals. In particular, the adsorption of such layer on copper is considered to be favoured when copper oxides already exist on the surface of the metal [5,13-17], though the formation of a complex film of the inhibitor on the base metal has also been reported [5,18-21]. Though adsorption at the surface is regarded to be the first step in the process [15,22], the actual mechanism is not yet fully ascertained, neither the chemical nature of the resulting inhibitor films is completely established, though the knowledge of both is necessary towards the development of new and more effective inhibitors.

2-Mercaptobenzimidazole (MBI) has been found to be more effective than BTAH for the corrosion protection of copper in aerated $\mathrm{HCl}$ aqueous environment [23], and its inhibitive action is exerted mainly on the anodic process. Conversely to BTAH, The MBI molecule $\left(\mathrm{C}_{7} \mathrm{H}_{4} \mathrm{~N}_{2} \mathrm{~S}\right)$ contains two nitrogen atoms, and deprotonation of the imine group originates the anionic species $\mathrm{MBI}^{-}$and $\mathrm{MBI}^{2-}$, which are aromatic too. It is this negative charge distribution extended over several atoms (namely sulphur and nitrogen) that favours direct bonding to copper cations, and each metal ion is directly coordinated to two ligands. Furthermore, $\mathrm{MBI}$ contains a sulphur atom that is strongly adsorbed on the copper surface. This is the rationale behind the formation of a polymeric structure on the copper surface with the participation of MBI molecules. A variety of experimental techniques have been employed to characterize copper-MBI films, including cyclic voltammetry, electrochemical impedance spectroscopy, elemental surface analysis, infrared spectroscopy and mass spectrometry [24,25], thus making the copper-MBI system an attractive model for the investigation of the applicability of new experimental techniques and methods.

In recent years, a variety of scanning microelectrochemical techniques has been introduced in corrosion laboratory facilitating the spatially-resolved investigation of the corrosion reactions and the surface films involved in them, in the micrometric and submicrometric scales [26,27]. Among them, the scanning vibrating electrode technique (SVET) [28] has been the most effectively employed to characterize the inhibiting effect of inhibitor systems for the protection of metals and alloys [29-35], the inhibition at defects and cut edges in painted metals [36-41], and the formulation of self-healing coatings [42-45]. Conversely, the scanning electrochemical microscope (SECM) has been scarcely employed to investigate metal-inhibitor systems besides the pioneering work of Kontturi and coworkers [46-48], though this technique has found the widest range of applications in the study of corrosion reactions and corrosion protection systems [49-51] among the microelectrochemical techniques. Since we consider SECM can be a valuable technique to 
investigate the anti-corrosion performance of inhibitor films, we decided to explore its applicability to characterize the layers formed by 2-mercaptobenzimidazole on copper.

This paper reports on SECM and SVET studies of the surface films formed by MBI on copper, taking into account the anticorrosion protection characteristics and stability of the layers formed in either $\mathrm{KCl}$ or $\mathrm{Na}_{2} \mathrm{SO}_{4}$ aqueous solutions. The samples were left unpolarized in the test medium, which was maintained at room temperature and open to air. SECM was operated in the feedback mode by adding ferrocene-methanol as redox mediator, thus allowing for the surface conductivity properties of the copper-MBI films to be determined, and the surface chemical reactivity of samples displaying various regions with different inhibitor coverages to be imaged. On the other hand, SVET was used in order to measure the local distribution of the current density on the copper surfaces with and without MBI. In this technique, the ionic current flow due to metal corrosion results in a very minute electric field within an electrolyte medium, which can be image as the distribution of potentials and currents on the electrolytic phase in contact with the surface of the sample.

\section{2.- Experimental}

SECM and SVET measurements were performed on 99.99\% purity copper plates, supplied

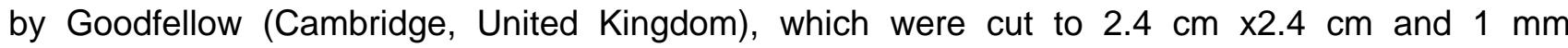
thickness. The surface of the samples was ground mechanically using metallographic emery paper of increasing fineness of 800,1200 and 4000 grit, degreased with acetone, rinsed with MilliQ grade water and dried to air. For the preparation of the inhibitive films on the copper samples, the metal plates were immersed either in $0.1 \mathrm{M} \mathrm{KCl}+1 \mathrm{mM} \mathrm{MBI}$ or in $0.1 \mathrm{M} \mathrm{Na}_{2} \mathrm{SO}_{4}+1 \mathrm{mM} \mathrm{MBI}$ aqueous solutions for different immersion times ranging from a few seconds up to 7 days.

SECM experiments were carried out using a scanning electrochemical microscope from Sensolytics (Bochum, Germany). Platinum microelectrodes of $10 \mu \mathrm{m}$ diameter served as SECM tips. The tip-sample distance for SECM imaging was determined upon comparison of the approach curve recorded over a copper surface with the theoretical one assuming that the reduction of the mediator at the surface was under kinetic control [52]. Imaging was performed with the microelectrode at a height of $15 \mu \mathrm{m}$ over the specimen surface. The SECM cell with the sample was mounted horizontally facing upwards at the bottom of a microflat cell [53]. An $\mathrm{Ag} / \mathrm{AgCl} / \mathrm{KCl}(3 \mathrm{M})$ and a 316L stainless steel wire served as reference and counter electrodes, respectively. Ferrocenemethanol (Aldrich) was used as mediator.

SVET measurements were made using a system from Applicable Electronics (Forestdale, MA, USA). The vibrating probe consisted of a $20 \mu \mathrm{m}$ platinum-black-coated tip that was placed above the surface of the substrate at a height of $60 \mu \mathrm{m}$. The vibrating amplitudes of the scanning 
probe were adjusted to 30 and $20 \mu \mathrm{m}$, parallel and normal to the surface, respectively. Two platinum wires served as signal and reference electrodes. When all adjustments had been made, about $5 \mathrm{~mL}$ of electrolyte solution was added to the cell and the three electrodes were subsequently placed in the solution. A Video-microscope was employed to establish the tip-sample distance and to record images of the most significant features on the substrate surface in situ at real time.

The test electrolytes employed in the microelectrochemical experiments were $1 \mathrm{mM} \mathrm{Na}_{2} \mathrm{SO}_{4}$ containing $1 \mathrm{mM}$ ferrocene-methanol as redox mediator for SECM, and 10 and $50 \mathrm{mM} \mathrm{KCl}$ solutions for SVET. All aqueous solutions were prepared using MilliQ water. Measurements were performed in naturally aerated solutions at ambient conditions $\left(22^{\circ} \mathrm{C}\right)$.

\section{3.- Results and discussion}

\subsection{Monitoring of surface reactivity changes during early stages of Cu-MBI formation.}

SECM in the feedback mode probes surface reactivity towards the oxidation of ferrocenemethanol of the investigated area located under the SECM tip. Z-approach curves monitor the tip current as the ultramicroelectrode approaches the sample. In the case of a conducting surface such as that of a fresh copper sample, the corresponding increase of the faradaic current is related to the mediator's regeneration at the sample surface (i.e., positive feedback). In the case of the metallic material covered by an inhibitor film, the surface reactivity reflects mainly the ability to transport charge within the surface film and eventually may result in an insulating surface. In the latest case, the substrate sample does not regenerate the mediator, and effectively becomes a geometrical blockage towards the diffusion of the mediator from the bulk electrolyte. Smaller currents are then measured as the tip approaches the substrate (i.e., negative feedback). The copper substrates for SECM measurements were pre-treated by immersing them during different times in inhibitorcontaining solutions, using either $0.1 \mathrm{M} \mathrm{Na}_{2} \mathrm{SO}_{4}$ or $0.1 \mathrm{M} \mathrm{KCl}$ as supporting electrolytes. The choice of supporting electrolytes would facilitate to observe the eventual influence of the smaller chloride ions towards the adsorption of the inhibitor on the metal surfaces. Next, the samples were placed in the SECM flat microcell, a controlled amount of the test electrolyte (namely, $1 \mathrm{mM} \mathrm{Na}_{2} \mathrm{SO}_{4}+1 \mathrm{mM}$ ferrocene-methanol) was added, and the corresponding Z-approach curves were measured starting from a fixed height. Figure 1 depicts the plots measured for copper samples pre-treated in either 0.1 $\mathrm{M} \mathrm{Na}_{2} \mathrm{SO}_{4}$ or in $0.1 \mathrm{M} \mathrm{KCl}$. Inspection of these graphs allows for the observation of a full transition from pure positive feedback behaviour characteristic of untreated copper to a negative feedback regime for the thickest inhibitor films produced after 7 days pre-treatment. Changes in the kinetics of inhibitor adsorption from the two supporting electrolytes can be deduced from the comparison of the approach curves measured for samples with the same duration of the pre-treatment step. Figure 2 
shows the time dependence of the tip current measured at the distance of maximum approach to the substrate, and in all cases significantly smaller currents are found for the samples pre-treated in the presence of chloride ions. This is strong evidence that chloride ions participate in the formation of the inhibitor film when present in the environment, and that the formed layers hinder charge transfer more efficiently. That is, a greater inhibiting effect is provided when chloride ions are present in the electrolyte, which may support previous reports on the incorporation of chloride to the protective layers formed on copper in the presence of MBI [15].

Similar conclusions could be derived by using the SECM in the imaging mode using ferrocene-methanol as redox mediator for feedback operation. In this case, copper samples were subjected to a sequence of immersion steps in the inhibitor-containing electrolyte to prepare surfaces with four regions of different coverage by the inhibitor. This was achieved by dipping half of the sample into the treatment electrolyte for a given time $\left(t_{1}\right)$, carefully removing the sample, rotating the sample by $90^{\circ}$, and new immersion of a half of the surface in the electrolyte for another controlled period $\left(t_{2}\right)$. In this way, four regions were developed on the surface that corresponded namely to exposures $0, t_{1}, t_{2}$, and $t_{1}+t_{2}$. The sample was then placed in the SECM flat microcell, and the test electrolyte $1 \mathrm{mM} \mathrm{Na}_{2} \mathrm{SO}_{4}+1 \mathrm{mM}$ ferrocene-methanol was carefully added. Then, the tip was rastered over the substrate at a constant height of $15 \mu \mathrm{m}$ by using an $X-Y$ grid centered in the sample, thus allowing pass above the four regions in a single scan. Figure 3 depicts the SECM images recorded for samples pre-treated in $0.1 \mathrm{M} \mathrm{Na}_{2} \mathrm{SO}_{4}$ and in $0.1 \mathrm{M} \mathrm{KCl}$ solutions containing 1 $\mathrm{mM} \mathrm{MBI}$, respectively. They were obtained using $t_{1}=5 \mathrm{~min}$ and $t_{2}=10 \mathrm{~min}$. Though the samples are topographically flat for the vertical resolution of the technique employed, the regions of different inhibitor coverage are clearly displayed in the SECM images due to the variations in the faradaic current measured at the tip for ferrocene-methanol that are measured above each zone. The tip currents are always smaller over the areas covered by the inhibitor, and can be clearly observed in the images for the rather short pre-treatments of $5 \mathrm{~min}$. Longer pre-treatments with $\mathrm{MBI}$ deliver surface portions with even smaller currents at the tip when passing above them. This is a clear indication that the thickness of the inhibitor layer increases with longer pre-treatments, and these surface layers hinder the charge conductivity, thus protecting the metal from oxidation. Again, the enhanced inhibiting effect of MBI films formed in chloride-containing environments can be derived from the comparison of the images in Figure 3. Indeed, the reduction in the faradaic currents measured at the tip after 15 min pre-treatment amounts to ca. 50\% for the sample prepared in the chloride-containing solution, whereas it is only $35 \%$ for that fabricated in the chloride-free electrolyte. 
Considering the persistence of inhibitor films formed on a metal for anticorrosion protection, one can design experiments that would allow their susceptibility to attack by an aggressive environment to be investigated using scanning microelectrochemical techniques.

It was shown above that SECM could be employed to image copper samples prepared to present various regions of different surface finishes. A variation from the procedure employed in Section 3.1 was performed this time, such that the sequence and the nature of the pre-treatment steps would allow the stability of inhibitor films to be explored instead. In the new procedure, the first step involved the complete immersion of the copper sample in $0.1 \mathrm{M} \mathrm{KCl}+1 \mathrm{mM} \mathrm{MBI}$ solution for 7 days. This electrolyte was chosen on the basis of the results described in Section 3.1 corresponding to thicker and less conductive surface layers. The duration of this step was also selected to be greatly in excess of what is required to form the thickest inhibitor film exclusively by immersion. After 7 days, the sample was removed from the inhibitor-containing electrolyte, rinsed with high-purity deionized water to secure the removal of inhibitor molecules in the thin electrolyte layer wetting the samples, and then dried under a flow of air. The corrosive attack was subsequently performed in 3 wt. $\% \mathrm{NaCl}$ solution for various times, namely with $t_{1}=6 \mathrm{~h}$ and $t_{2}=12 \mathrm{~h}$ to develop four regions on the surface corresponding to exposures $0,6,12$, and $18 \mathrm{~h}$. Upon immersion of this sample in $1 \mathrm{mM}$ $\mathrm{Na}_{2} \mathrm{SO}_{4}+1 \mathrm{mM}$ ferrocene-methanol, the tip-substrate distance for SECM operation was established by measuring the $Z$-approach curve over the intact $\mathrm{Cu}-\mathrm{MBI}$ surface, though the curve-modelling was done for the case of negative feedback this time [52].

Figure 4 shows the SECM image for this sample. The trend exhibited by the tip currents measured over the various regions is now the opposite that described above. Namely, faradaic currents at the tip are higher over the zones with longer exposures to the $3 \mathrm{wt} \% \mathrm{NaCl}$ solution, thus indicating partial removal of the protective layer or a loss in its insulating properties during the attack by chloride ions. Nevertheless, the great performance of the inhibitor film produced on copper is demonstrated in this case, because attacks in excess of 24 hours in this highly aggressive electrolyte were necessary for current measured at the tip to exhibit the same values as in the bulk of the electrolyte. This would correspond to the transition from negative to positive feedback regimes, though it must be realized that this is only an apparent observation. That is, the slow kinetics of charge transfer for the mediator regeneration at the surface (i.e., positive feedback) results in the measurement of values very close to $i_{\text {lim }}$ when the tip is placed in the proximity of the surface portion attacked for 24 hours.

In this case, SVET could also be used in addition to SECM operated in the feedback mode, thus allowing for the visualization of ionic current flows occurring in the electrolytic phase in contact 
with the sample as result of the corrosive process. That is, the onset of corrosive attack on the copper samples protected by $\mathrm{MBI}$ would result from the establishment of anodes and cathodes at the micrometer scale. The test environment was $10 \mathrm{mM} \mathrm{KCl}$ this time, since SVET resolution requires the use of poorly conductive electrolytes. Thus, the electrolyte responsible for the corrosive attack is less aggressive that the one employed in the SECM experiments, which hinders a quantitative comparison of the results obtained with the two scanning microelectrochemical techniques. Yet, qualitative trends could be found as described next.

Figure 5 shows the SVET images measured for a sample that was protected by a thin inhibitor film after immersion for $10 \mathrm{~s}$ in the MBI-containing electrolytes. Though the optical micrograph in Figure $5 d$ recorded after 21 hours immersion in the test electrolyte does not show any clear evidence of corrosive attack, the SVET maps consistently depict anodic activity occurring from the inhibitor film formed in $\mathrm{Na}_{2} \mathrm{SO}_{4}$ solution, even in the image started to record as early as $10 \mathrm{~s}$ after initiating the exposure of the sample to the measurement environment (see Figure $5 \mathrm{a}$ ). This result is in agreement with the previous observations that inhibitor films formed by $\mathrm{MBI}$ on copper have superior corrosion protection characteristics when chloride ions are also involved. The high resolution of SVET to resolve differences in chemical reactivity from one sample has also been demonstrated even from very early exposures.

The reported behaviour is more clearly observed when higher concentrations of $\mathrm{KCl}$ are employed, as it is the case for the SVET images shown in Figure 6. The onset of the corrosive attack is now clearly displayed, with the anodes occurring on the Cu-MBI zone formed in the chloride-free solution. The degradation of the inhibitor film results in higher corrosion rates as time elapses. Though initially very low corrosion rates are measured over the surface (Figure 6a), the cationic flow is greater by several orders of magnitude once the first pit is observed after 4 hours exposure to the corrosive medium (see Figure $6 \mathrm{~b}$ ). The corrosion reaction becomes even more violent for longer exposures with the nucleation of additional pits in the zone pre-treated in the sulphate environment (cf. Figures $6 c$ and d). It is important to observe that the cathodes are not observed over the Cu-MBI film formed in the chloride environment at any time, including the image recorded after 24 hours exposure (Figure 6d) even when plotted under magnification (Figure 6e). The insulating characteristics of the inhibitor film are thus confirmed, whereas the cathodes were to be found in the region pre-treated in sulphate as well (cf. Figure 6e).

In summary, the use of scanning microelectrochemical techniques demonstrates that the polymeric film formed on copper by $\mathrm{MBI}$ in the presence of chloride ions provides enhanced anticorrosion protection for the metal. In the case of very short pre-treatments (namely $10 \mathrm{~s}$ ), though some protection is conferred to the base metal, charge conductivity through the film still occurs. This effect is more noticeable in the case of the inhibitor films formed in the absence of chloride, and SVET images show the distribution of microanodes and microcathodes under the film at the onset of the corrosion process. 


\section{4.- Conclusions}

Investigations performed in this work showed that scanning microelectrochemical techniques can give valuable information regarding the protection characteristics and the kinetics of inhibitor films formed on metals, as illustrated by the inhibition of copper corrosion by 2mercaptobenzimidazole. This study confirmed that even changes in the composition of the base electrolyte induce a significant effect on the inhibiting properties of the organic compound, thus chloride ions promoting the formation of thicker and more insulating layers than those formed in sodium sulphate solution.

SECM operated in the feedback mode and SVET techniques provides complementary information on corrosion and inhibition processes, with the great advantage that variations in the chemical reactivity at the surface of the samples can be spatially resolved.

\section{Acknowledgments:}

This work was supported by the Ministerio de Ciencia e Innovación (Madrid, Spain) and the European Regional Development Fund (Brussels, Belgium) under Grant Number CTQ200912459/PPQ. JI and JJS thank the Agencia Canaria de Investigación (Canary Islands, Spain) for the award of a doctoral grant and a mobility grant, respectively.

\section{References:}

1. G.W. Poling, Reflection infra-red studies of films formed by benzotriazole on Cu, Corros. Sci. 10 (1970) 359-370.

2. T. Notoya, G.W. Poling, Topographies of thick Cu-benzotriazolate-films on copper, Corrosion 32 (1976) 216-223.

3. D. Chadwick, T. Hashemi, Adsorbed corrosion inhibitors studied by electron spectroscopy: Benzotriazole on copper and copper alloys, Corros. Sci. 18 (1978) 39-51.

4. D. Tromans, R. Sun, Anodic polarization behavior of copper in aqueous chloride/benzotriazole solutions, J. Electrochem. Soc. 138 (1991) 3235-3244.

5. G. Xue, X.-Y. Huang, J. Dong, J. Zhang, The formation of an effective anti-corrosion film on copper surfaces from 2-mercaptobenzimidazole solution, J. Electroanal. Chem. 310 (1991) 139148. 
6. M.Th. Makhhuf, S.A. El-Shatory, A. El-Said, The synergistic effect of halide ions and some selected thiols as a combined corrosion inhibitor for pickling of mild steel in sulphuric acid solution, Mater. Chem. Phys. 43 (1996) 76-82

7. L. Wang, Evaluation of 2-mercaptobenzimidazole as corrosion inhibitor for mild steel in phosphoric acid, Corros. Sci. 43 (2001) 2281-2289.

8. S.A.M. Refaey, F. Taha, A.M. Abd El-Malak, Corrosion and inhibition of 316L stainless steel in neutral medium by 2-mercaptobenzimidazole, Int. J. Electrochem. Sci. 1 (2006) 80-91.

9. M. Mahdavian, S. Ashhari, Corrosion inhibition performance of 2-mercaptobenzimidazole and 2mercaptobenzoxazole compounds for protection of mild steel in hydrochloric acid solution, Electrochim. Acta 55 (2009) 1720-1724.

10. J. Aljourani, K. Raeissi, M.A. Goloza, Benzimidazole and its derivatives as corrosion inhibitors for mild steel in $1 \mathrm{M} \mathrm{HCl} \mathrm{solution,} \mathrm{Corros.} \mathrm{Sci.} 51$ (2009) 1836-1843.

11. L. Wang, J.-X. Pu, H.-Ch. Luo, Corrosion inhibition of zinc in phosphoric acid solution by 2mercaptobenzimidazole, Corros. Sci. 45 (2003) 677-683.

12. B. Assouli, A. Srhiri and H. Idrissi, Effect of 2-mercaptobenzimidazole and its polymeric film on the corrosion inhibition of brass (60/40) in ammonia solution, Corrosion 60 (2004) 399-407.

13. H.G. Tompkins, S.P. Sharma, The interaction of imidazole, benzimidazole and related azoles with a copper surface, Surf. Interface Anal. 4 (1982) 261-266.

14. S. Yoshida, H. Ishida, The effect of surface oxide layers on the oxidative behaviour of imidazoletreated copper, J. Mater. Sci. 19 (1982) 2323-2335.

15. D. Chadwick, T. Hashemi, Electron spectroscopy of corrosion inhibitors: Surface films formed by 2-mercaptobenzothiazole and 2-mercaptobenzimidazole on copper, Surf. Sci. 89 (1979) 649659.

16. S. Yoshida, H. Ishida, The effect of chain length on the thermal stability of 2-alkylimidazoles on copper and 2-alkylimidazolato copper(II) complexes, Appl. Surf. Sci. 20 (1985) 497-511.

17. C. McCrory-Joy, J.M. Rosamilia, Modification of the electrochemical behavior of copper by azole compounds, J. Electroanal. Chem. 136 (1982) 105-118.

18. G. Xue, Q. Dai, S. Jiang, Chemical reactions of imidazole with metallic silver studied by the use of SERS and XPS techniques, J. Am. Chem. Soc. 110 (1988) 2393-2395.

19. G. Xue, J. Zhang, G. Shi, Y. Wu, Spectroscopic studies on the polymerization of benzimidazole with metallic copper, J. Chem. Soc. Pekin Trans. II (1989) 33-36.

20. G. Xue, J. Ding, P. Wu, G. Ji, The formation of a compact polymer film on a copper electrode from benzimidazole solution, J. Electroanal. Chem. 270 (1989) 163-173.

21. G. Xue, P. Wu, R. Chen, Air-oxidation of gold metal in polybenzimidazole solution, J. Chem. Soc., Chem. Commun. (1990) 495-497. 
22. G. Trabanelli, V. Carrassiti, Mechanism and phenomenology of organic inhibitors, in: Advances in Corrosion Science and Technology, Vol. 1 (Eds: M.G. Fontana, R.W. Staehle), Plenum Press, New York, 1970, pp. 147-227.

23. D.-Q. Zhang, L.-X. Gao, G.-D. Zhou, Inhibition of copper corrosion in aerated hydrochloric acid solution by heterocyclic compounds containing a mercapto group, Corros. Sci. 46 (2004) 30313040.

24. F.X. Perrin, J. Pagetti, Characterization and mechanism of direct film formation on a $\mathrm{Cu}$ electrode through electro-oxidation of 2-mercaptobenzimidazole, Corros. Sci. 40 (1998) 16471662.

25. J. Aljourani, K. Raeissi, M.A. Golozar, Benzimidazole and its derivatives as corrosion inhibitors for mild steel in 1M HCl solution, Corros. Sci. 51 (2009) 1836-1843.

26. Analytical Methods in Corrosion Science and Engineering (Eds: P. Marcus, F. Mansfeld), CRC Press, Boca Raton (FL), 2006.

27. Local Probe Techniques for Corrosion Research (Eds: R. Oltra, V. Maurice, R. Akid, P. Marcus), Woodhead, Cambridge, 2007.

28. R.S. Lillard, Scanning electrode techniques for investigating near-surface solution current densities, in: Analytical Methods in Corrosion Science and Engineering, (Eds: P. Marcus, F. Mansfeld), CRC Press, Boca Raton (FL), 2006, p. 571.

29. H.E. Jamil, A. Shriri, R. Boulif, C. Bastos, M.F. Montemor, M.G.S. Ferreira, Electrochemical behaviour of amino alcohol-based inhibitors used to control corrosion of reinforcing steel, Electrochim. Acta 49 (2004) 2753-2760.

30. A.C. Bastos, M.G.S. Ferreira, A.M. Simões, Comparative electrochemical studies of zinc chromate and zinc phosphate as corrosion inhibitors for zinc, Prog. Org. Coat. 52 (2005) 339350.

31. A.C. Bastos, M.G.S. Ferreira, A.M. Simões, Corrosion inhibition by chromate and phosphate extracts for iron substrates studied by EIS and SVET, Corros. Sci. 48 (2006) 1500-1512.

32. A.C. Bastos, M.L. Zheludkevich, M.G.S. Ferreira, A SVET investigation on the modification of zinc dust reactivity, Prog. Org. Coat. 63 (2008) 282-290.

33. G. Williams, A.J. Coleman, H.N. McMurray, Inhibition of aluminium alloy AA2024-T3 pitting corrosion by copper complexing compounds, Electrochim. Acta 55 (2010) 5947-5958.

34. G. Williams, H.N. McMurray, R. Grace, Inhibition of magnesium localised corrosion in chloride containing electrolyte, Electrochim. Acta 55 (2010) 7824-7833.

35. S. Kallip, A.C. Bastos, M.L. Zheludkevich, M.G.S. Ferreira, A multi-electrode cell for highthroughput SVET screening of corrosion inhibitors, Corros. Sci. 52 (2010) 3146-3149.

36. I.M. Zin, S.B. Lyon, A. Hussain, Under-film corrosion of epoxy-coated galvanised steel. An EIS and SVET study of the effect of inhibition at defects, Prog. Org. Coat. 52 (2005) 126-135. 
37. F. Thébault, B. Vuillemin, R. Oltra, K. Ogle, C. Allely, Investigation of self-healing mechanism on galvanized steels cut edges by coupling SVET and numerical modeling, Electrochim. Acta 53 (2008) 5226-5234.

38. A.M. Simões, J. Torres, R. Picciochi, J.C.S. Fernández, Corrosion inhibition at galvanized steel cut edges by phosphate pigments, Electrochim. Acta 54 (2009) 3857-3865.

39. O.V. Karavai, A.C. Bastos, M.L. Zheludkevich, M.G. Taryba, S.V. Lamaka, M.G.S. Ferreira, Localized electrochemical study of corrosion inhibition in microdefects on coated AZ31 magnesium alloy, Electrochim. Acta 55 (2010) 5401-5406.

40. A.M. Simões, J.C.S. Fernández, Studying phosphate corrosion inhibition at the cut edge of coil coated galvanized steel using the SVET and EIS, Prog. Org. Coat. 69 (2010) 219-224.

41. J.V. Custodio, S.M.L. Agostinho, A.M.P. Simões, Electrochemistry and surface analysis of the effect of benzotriazole on the cut edge corrosion of galvanized steel, Electrochim. Acta 55 (2010) 5523-5531.

42. S.V. Lamaka, M.L. Zheludkevich, K.A. Yasakau, M.F. Montemor, P. Cecílio, M.G.S. Ferreira, $\mathrm{TiO}_{x}$ self-assembled networks prepared by templating approach as nanostructured reservoirs for self-healing anticorrosion pre-treatments, Electrochem. Commun. 8 (2006) 421-428.

43. S.V. Lamaka, M.L. Zheludkevich, K.A. Yasakau, R. Serra, S.K. Poznyak, M.G.S. Ferreira, Nanoporous titania interlayer as reservoir of corrosion inhibitors for coatings with self-healing ability, Prog. Org. Coat. 58 (2007) 127-135.

44. A.F. Galio, S.V. Lamaka, M.L. Zheludkevich, L.F.P. Dick, I.L. Müller, M.G.S. Ferreira, Inhibitordoped sol-gel coatings for corrosion protection of magnesium alloy AZ31, Surf. Coat. Technol. 204 (2010) 1479-1486.

45. D. Snihirova, S.V. Lamaka, M. Taryba, A.N. Salak, S. Kallip, M.L. Zheludkevich, M.G.S. Ferreira, M.F. Montemor, Hydroxyapatite microparticles as feedback-active reservoirs of corrosion inhibitors, Appl. Mater. Interf. 2 (2010) 3011-3022.

46. K. Mansikkamaki, P. Ahonen, G. Fabricius, L. Murtomaki, K. Kontturi, Inhibitive effect of benzotriazole on copper surfaces studied by SECM, J. Electrochem. Soc. 152 (2005) B12-B16.

47. K. Mansikkamaki, C. Johans, K. Kontturi, The effect of oxygen on the inhibition of copper corrosion with benzotriazole, J. Electrochem. Soc. 153 (2006) B22-B24.

48. K. Mansikkamaki, U.Haapanen, C. Johans, K. Kontturi, M. Valden, Adsorption of benzotriazole on the surface of copper alloys studied by SECM and XPS, J. Electrochem. Soc. 153 (2006) B22-B24

49. S.E. Pust, W. Maier, G. Wittstock, Investigation of localized catalytic and electrocatalytic processes and corrosion reactions with scanning electrochemical microscopy (SECM), Z. Phys. Chem. 222 (2008) 1463-1517.

50. L. Niu, Y. Yin, W. Guo, M. Lu, R. Qin, S. Chen, Application of scanning electrochemical microscope in the study of corrosion of metals, J. Mater. Sci. 44 (2009) 4511-4521. 
51. R.M. Souto, S.V. Lamaka, S. González, Uses of scanning electrochemical microscopy in corrosion research, in: Microscopy: Science, Technology, Applications and Education, Vol. 3, (Eds: A. Méndez-Vilas, J. Díaz), Formatex, Badajoz, 2010, pp. 1769-1780.

52. Scanning Electrochemical Microscopy, (Eds: A.J. Bard, M.V. Mirkin), Marcel Dekker, New York, 2001, p. 243.

53. R.M. Souto, Y. González-García, J. Izquierdo, S. González, Examination of organic coatings on metallic substrates by scanning electrochemical microscopy in feedback mode: Revealing the early stages of coating breakdown in corrosive environments, Corros. Sci. 52 (2010) 748-753.

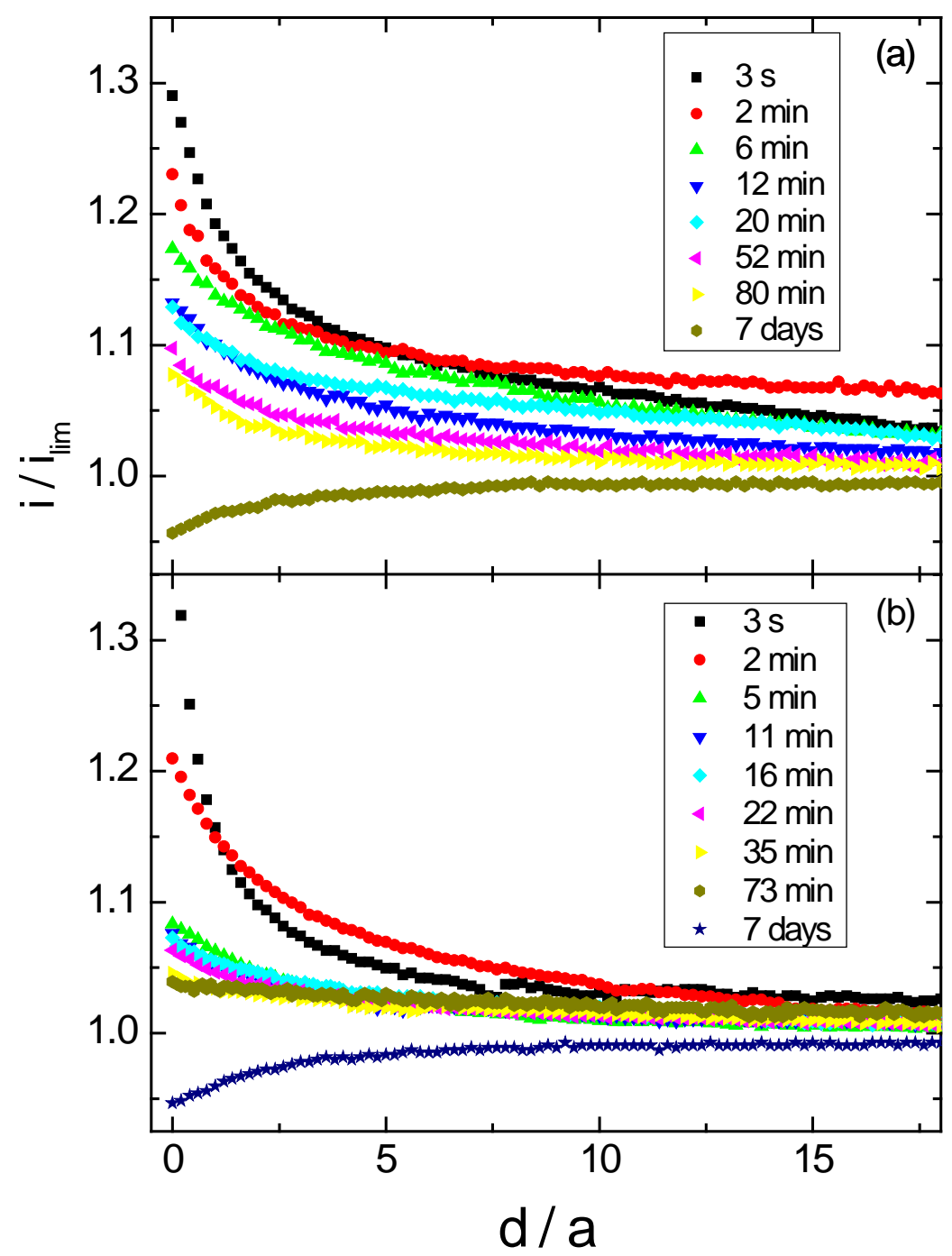

Figure 1: SECM normalized Z-approach curves towards inhibitor pre-treated copper surfaces measured in $1 \mathrm{mM} \mathrm{Na} 2 \mathrm{SO}_{4}+1 \mathrm{mM}$ ferrocene-methanol solution with a $10 \mu \mathrm{m}$ Pt electrode. Tip potential: $+0.50 \mathrm{~V}$ vs. $\mathrm{Ag} / \mathrm{AgCl}, \mathrm{KCl}(3 \mathrm{M})$. The copper samples were pre-treated by immersion in: (a) $0.1 \mathrm{M} \mathrm{Na}_{2} \mathrm{SO}_{4}+1 \mathrm{mM} \mathrm{MBI}$, and (b) $0.1 \mathrm{M} \mathrm{KCl}+1 \mathrm{mM} \mathrm{MBI}$ for the times indicated in the legends. $i / i_{\text {lim }}$ is the dimensionless tip current, and $d / a$ is the dimensionless distance between the sample and the tip. The samples were left at their spontaneous open circuit potentials in the test electrolyte. 


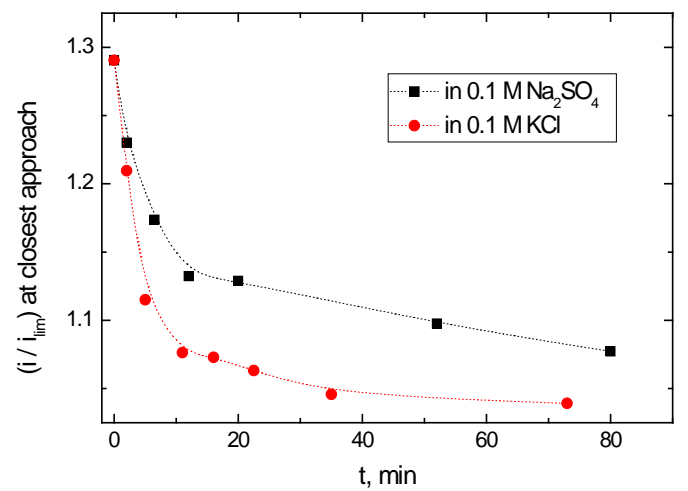

Figure 2: Time evolution of the normalized current values measured when the tip was placed at the closest distance attained during the measurement of the approach curves depicted in Fig. 1. The inhibitor molecule was contained in either $(\bullet) 0.1 \mathrm{M} \mathrm{KCl}$ or (ש) $0.1 \mathrm{M} \mathrm{Na}_{2} \mathrm{SO}_{4}$ aqueous solution.
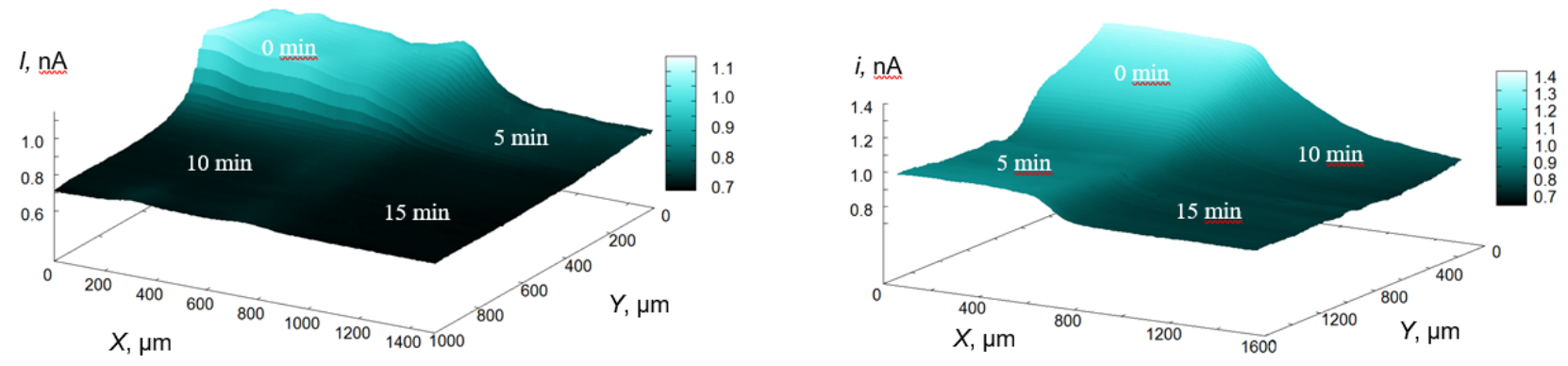

(a)

(b)

Figure 3: Images generated by SECM of copper samples treated with MBI for various times, as indicated in the figure. The solutions used for the pre-treatment of the copper samples were: (a) 0.1 $\mathrm{M} \mathrm{KCl}+1 \mathrm{mM} \mathrm{MBI}$ solution, and (b) $0.1 \mathrm{M} \mathrm{Na}_{2} \mathrm{SO}_{4}+1 \mathrm{mM} \mathrm{MBI}$ solution. The images were registered with a $10 \mu \mathrm{m}$ Pt electrode when the samples were exposed to $0.1 \mathrm{M} \mathrm{Na}_{2} \mathrm{SO}_{4}+1 \mathrm{mM}$ ferrocene-methanol solution. Tip-substrate distance: $15 \mu \mathrm{m}$. Tip potential: $+0.50 \mathrm{~V}$ vs. $\mathrm{Ag} / \mathrm{AgCl}$, $\mathrm{KCl}(3 \mathrm{M})$. The $Z$ scale is the tip current in $\mathrm{nA}$. $i_{\text {lim }}=0.99 \mathrm{nA}$. The samples were left at their spontaneous open circuit potentials in the electrolyte.

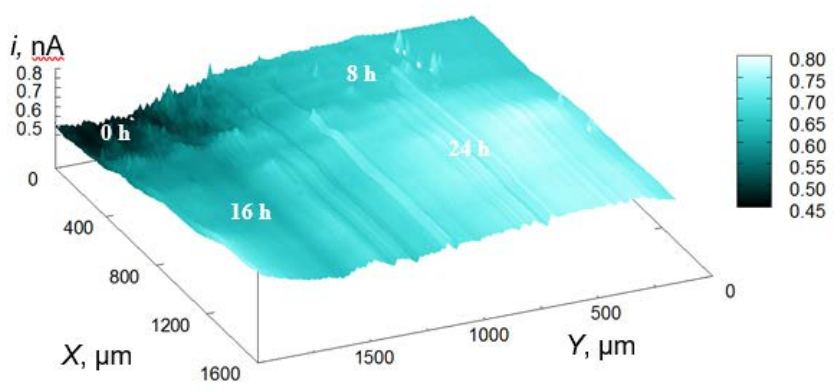

Figure 4: Image generated by SECM of a copper sample displaying 4 zones of different electrochemical activity during immersion in $0.1 \mathrm{M} \mathrm{KCl}+1 \mathrm{mM}$ ferrocene-methanol solution with a $25 \mu \mathrm{m}$ Pt electrode. The copper sample was first treated during 7 days in $0.1 \mathrm{M} \mathrm{KCl}+1 \mathrm{mM} \mathrm{MBI}$ solution to form a Cu-MBI inhibitive film. The corrosion resistance characteristics of the Cu-MBI inhibitive film was investigated by exposing the sample to $1 \mathrm{M} \mathrm{NaCl}$ solution for the various times indicated on the figure. Tip-substrate distance: $15 \mu \mathrm{m}$. Tip potential: $+0.50 \mathrm{~V}$ vs. Ag/AgCl, $\mathrm{KCl}$ (3M). The $Z$ scale is the tip current in nA. The sample was left at its spontaneous open circuit potential in the electrolyte. 

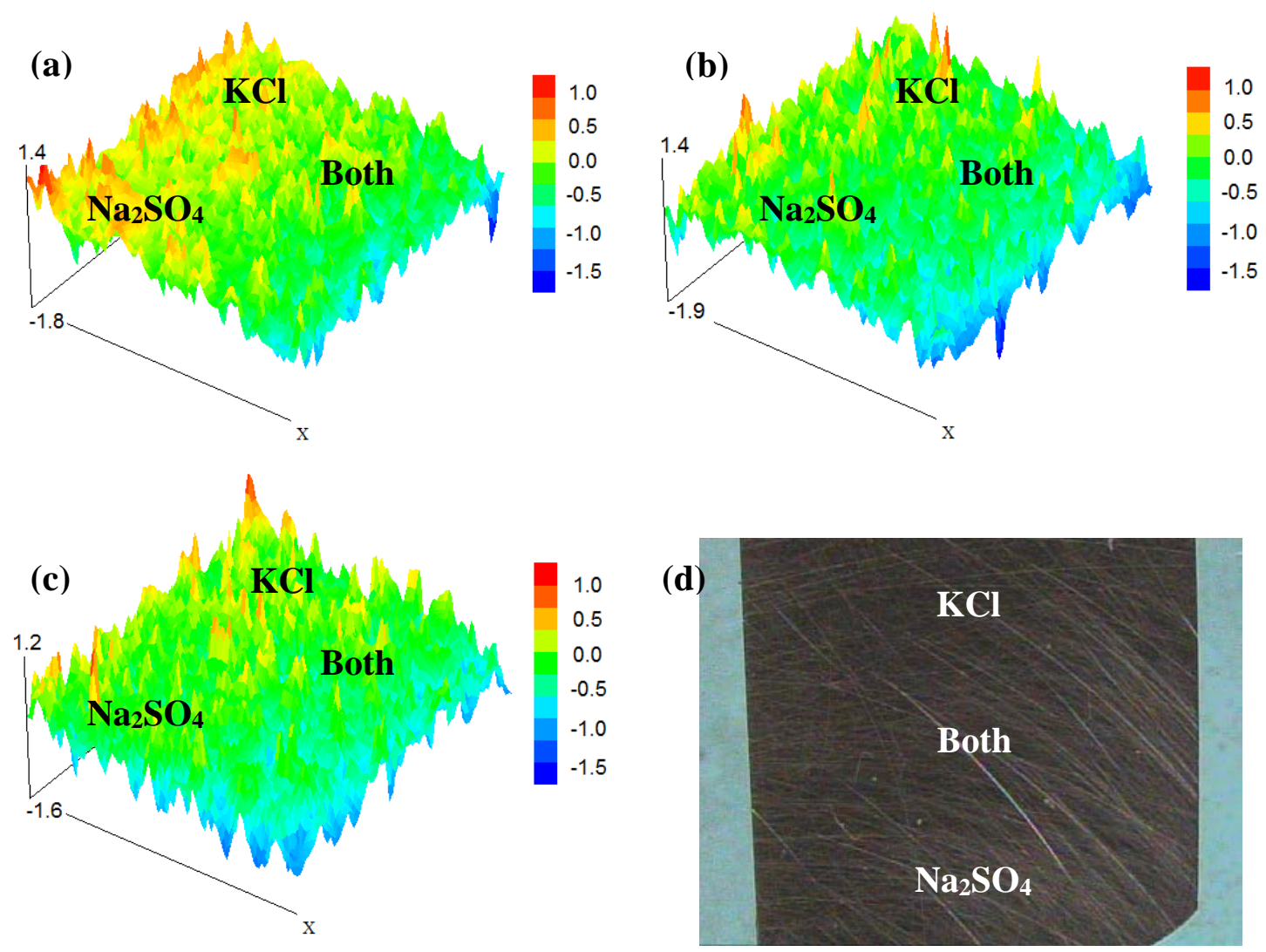

Figure 5: Images generated by SVET (a-c) and video microscope (d) of a Cu-MBI (10 s pretreatment in $0.1 \mathrm{M} \mathrm{KCl}+1 \mathrm{mM}$ MBI solution) - Cu-MBI (10 s pre-treatment in $0.1 \mathrm{M} \mathrm{Na}_{2} \mathrm{SO}_{4}+1$ mM MBI solution) system immersed in $10 \mathrm{mM} \mathrm{KCl}$ for (a) 1, (b) 9, and (c) $21 \mathrm{~h}$. The central part of the sample was immersed in both environments during the pre-treatment stage. Tip-substrate distance: $60 \mu \mathrm{m}$. The $Z$ scale is the ionic current in $\mu \mathrm{A} \mathrm{cm}{ }^{-2}$. The figures represent an area of 9000 $\mu \mathrm{m} \times 9000 \mu \mathrm{m}$ in $X$ and $Y$ directions. The sample was left at its spontaneous open circuit potential in the electrolyte. 


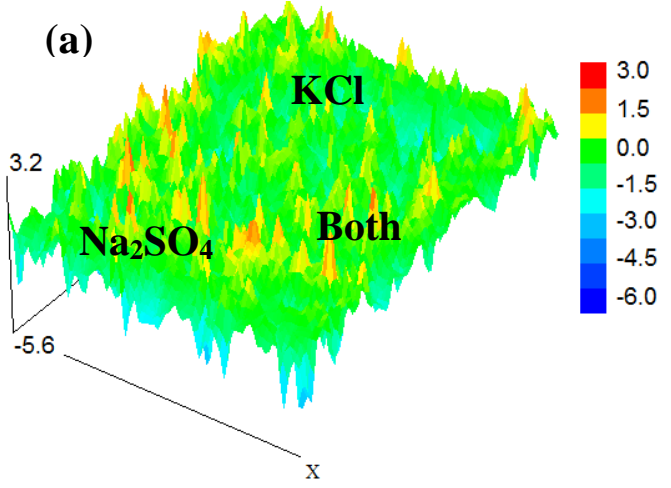

(c)

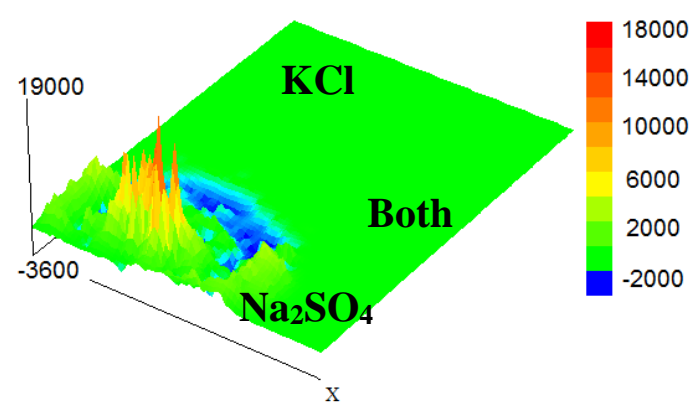

(b)

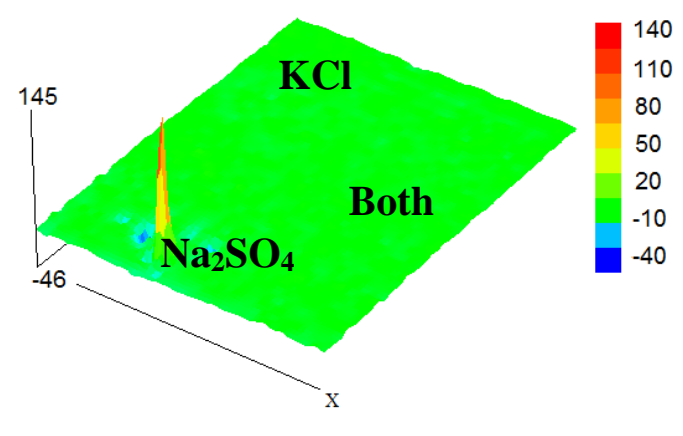

(d)

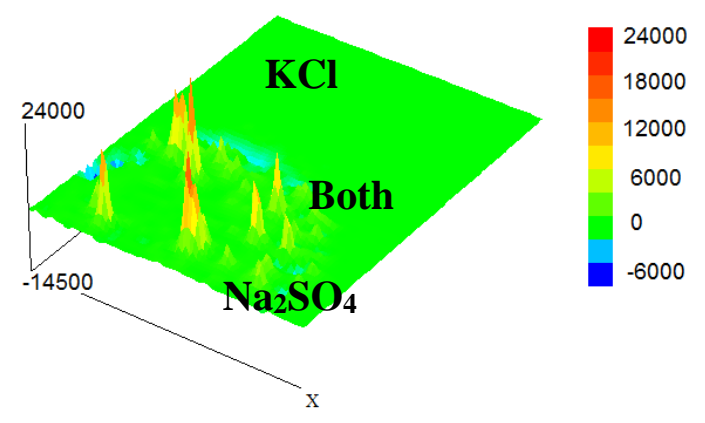

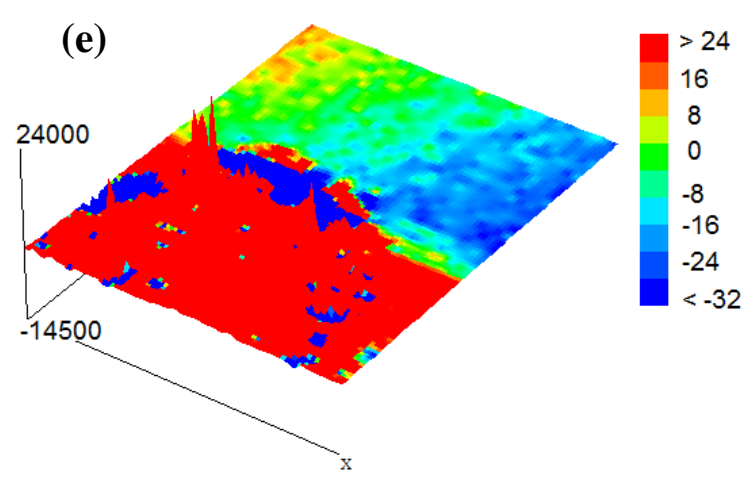

Figure 6: Images generated by SVET of a Cu-MBI $(10 \mathrm{~s}$ pre-treatment in $0.1 \mathrm{M} \mathrm{KCl}+1 \mathrm{mM} \mathrm{MBI}$ solution) - Cu-MBI (10 s pre-treatment in $0.1 \mathrm{M} \mathrm{Na}_{2} \mathrm{SO}_{4}+1 \mathrm{mM} \mathrm{MBI}$ solution) system immersed in $50 \mathrm{mM} \mathrm{KCl}$ for (a) 1.5, (b) 4, (c) 10, and (d,e) $24 \mathrm{~h}$. Tip-substrate distance: $60 \mu \mathrm{m}$. The $Z$ scale is the ionic current in $\mu \mathrm{A} \mathrm{cm}^{-2}$. The figures represent an area of $9000 \mu \mathrm{m} \times 9000 \mu \mathrm{m}$ in $X$ and $Y$ directions. The sample was left at its spontaneous open circuit potential in the electrolyte. 